\title{
Feminismos descoloniales latinoamericanos: geopolítica, resistencia y Relaciones Internacionales
}

\author{
Yetzy Urimar Villarroel Peña*
}

\begin{abstract}
Resumen
El feminismo descolonial latinoamericano nace con una fuerte influencia del feminismo autónomo latinoamericano que, a partir de 1980-1990, comenzó un proceso de desarrollo de pensamiento y prácticas políticas de resistencia para visibilizar la desigualdad de raza, etnia, clase, sexo y género en que viven buena parte de las mujeres de América Latina. Se propone desmontar la adscripción categorial de occidente tanto en lo académico como en lo político, por ello tiene vital importancia en y para las relaciones internacionales. Uno de los retos del pensamiento descolonial ha sido comprender la dimensión global y su conexión con lo local para repensar las posibles alternativas políticas a la globalización neoliberal y a la colonialidad, y en ese sentido adquiere carácter geopolítico. Interesa: 1) Explicar el feminismo descolonial en América Latina y diferenciarlo de otras formas de feminismo, especialmente, del feminismo postcolonial. 2) Determinar las fuentes de la cuales se nutre y las concepciones ontológicas, epistemológicas, estéticas y éticas que le caracterizan. 3) Determinar las prácticas políticas colectivas que le preceden y sus propuestas de transformación sociopolíticas y, finalmente, 4) revisar su utilidad en el ámbito de las Relaciones Internacionales. Se concluye que es un pensamiento altamente estratégico porque considera el valor de otras epistemologías, ontologías, éticas y estéticas para pensar el mundo fuera de los discursos de derecha e izquierda.
\end{abstract}

\section{Palabras clave}

Feminismos; descolonialidad; geopolítica; resistencia; Relaciones Internacionales.

\section{TITLE}

Latin American Descolonial Feminisms: Geopolitics, Resistance and International Relations
*Yetzy Urimar VILLARROEL PEÑA, Investigadora $y$ Profesora Asociada adscrita al Dpto. de Ciencias Sociales de la Universidad Simón Bolívar de Venezuela. Lic. en Estudios Internacionales con Maestría y Doctorado en Ciencia Política.

Recibido: 05/03/2018

Aceptado:

26/09/2018

\section{DOI:}

https://doi.

org/10.15366/relacionesinternacionales2018.39.006

\begin{abstract}
The Latin American decolonial feminism was born with a strong influence of the Latin American autonomous feminism that from 1980-1990 began a process of development of thought and political practices of resistance to make visible the inequality of race, ethnicity, class, sex and gender in which a good part of the women of Latin America live. It is proposed to dismantle the categorical ascription of the West both in the academic and in the political, for that reason it has vital importance in and for the International Relations discipline. One of the challenges of decolonial thinking has been to understand the global dimension and its connection with the local to rethink the possible political alternatives to neoliberal globalization and coloniality and in that sense it acquires geopolitical character. Interested in: 1) Explain decolonial feminism in Latin America and differentiate it from other forms of feminism, especially postcolonial feminism. 2) Determine the sources from which it is nourished and the ontological, epistemological, aesthetic and ethical conceptions that characterize it. 3) Determine the collective political practices that precede it and its proposals for socio-political transformation and finally 4) review its usefulness in the field of international relations. It is concluded that it is a highly strategic thought because it considers the value of other epistemologies, ontologies, ethics and aesthetics to think the world outside the discourses of right and left.
\end{abstract}

\section{KEYWORDS}

Feminisms, decoloniality, geopolitics, resistance, international relations. 


\section{ntroducción}

Antes de adentrarnos en los feminismos descoloniales latinoamericanos y comprender sus concepciones, sus prácticas y propuestas, es menester desentrañar del pensamiento crítico latinoamericano algunas fuentes de las cuales fueron surgiendo conceptos, ideasformas que permitieron la configuración de una filosofía latinoamericana ${ }^{1}$ y de la cual se va tejiendo una buena parte del pensamiento de la región. Todas estas fuentes son elementos que han sido absorbidos por el pensamiento latinoamericano y reelaborados desde la visión feminista para explicar y proponer prácticas políticas diversas que las mujeres han venido realizando en América Latina, desde otras miradas, desde otras perspectivas.

Como antecedentes al pensamiento descolonial se puede considerar la preocupación de pensadores del siglo XIX por la independencia cultural, a los cuales Leopoldo Zea les denominó próceres de la emancipación mental. Seguidamente, a quienes se opusieron al positivismo que se posicionó en América Latina y proponían desmarcarse del colonialismo en su versión de nordomanía o yanquimanía² para buscar la originalidad y autenticidad, entre ellos Leopoldo Zea, José Enrique Rodó, José Vasconcelos, José Carlos Mariátegui, Raúl Haya de la Torre. Durante el siglo XX, pero desde la mirada del colonizado negro de las Antillas, Aimé Césaire planteó el término negritud (negritude) en el periódico L'étudiant noir de 1934. Le seguió Frantz Fanon quien en 1952 escribió Piel negra, máscaras blancas donde se cuestionaba la obediencia del negro hacia quienes le desprecian y maltratan, encontrando la respuesta en esa colonización de la conciencia.

La decolonialidad como opción política internacional surge desde el Tercer Mundo, durante la Conferencia de Bandung de $1955^{3}$, Indonesia, en la cual participaron países africanos y asiáticos de reciente independencia para ese momento, como respuesta a las pretensiones coloniales y neocoloniales de las principales potencias mundiales, ocurrida en el marco de la Guerra Fría. De allí surge el Movimiento de los No Alineados, que tiene un fuerte impacto y convergencia con el pensamiento surgido desde América Latina.

Hacia las décadas de 1960 y 1970, en América Latina se generaron corrientes de pensamiento que denunciaban la condición de dependencia económica y cultural así como la injusticia social en la región; estas fueron la teoría de la dependencia, la teología de la

\footnotetext{
1 Es conocido el debate que entre filósofos latinoamericanos se presentó sobre si hay o no una filosofía auténtica latinoamericana, entre ellos se pueden nombrar a Augusto Salazar Bondy y a Leopoldo Zea. Para Leopoldo Zea. la región está consciente de no partir de un pensamiento auténtico y original, pero entiende que se han realizado reelaboraciones que la hacen distinta a la filosofía europea. Ver: ZEA, Leopoldo, La Filosofía Latinoamericana como Filosofía sin más, Siglo XXI, México, 1969. Ver también SALAZAR BONDY, Augusto, ¿Existe una filosofía de Nuestra América?, Siglo XXI, México, 1968.

2 La nordomanía fue el nombre que le otorgó Leopoldo Zea al "esfuerzo de las élites criollas de la periferia para imitar los modelos de desarrollo provenientes del norte, mientras reproducían las antiguas formas de colonialismo". ZEA, Leopoldo, "Introducción" en ZEA, Leopoldo (Ed.), América Latina en sus ideas, Unesco, Siglo XXI, México, 1986, pp. 16-17. La yanquimanía fue el adjetivo que utilizó José Enrique Rodó para referirse al mismo fenómeno.

3 "El principal objetivo de la conferencia era encontrar las bases y la visión común de un futuro que no fuera ni capitalista ni comunista. El camino que hallaron fue la 'descolonización' [...], desprenderse de las dos principales macronarrativas occidentales. Fue imitada por la conferencia de los Países No Alineados que tuvo lugar en Belgrado en 1961, en la cual varios países latinoamericanos sumaron sus fuerzas a los asiáticos y africanos". MIGNOLO, Walter, "Geopolítica de la sensibilidad y del conocimiento. Sobre (de) colonialidad, pensamiento fronterizo y desobediencia epistémica", 2011: http://eipcp.net/transversal/0112/mignolo/es [Consultado 12 de noviembre de 2017].
} 
liberación, la filosofía de la liberación y la pedagogía del pprimido. Luego, en la década de 1990, Aníbal Quijano, estudiando la modernidad, se encontró con la colonialidad del poder, la cual explicó como el lado oscuro de la modernidad, "un patrón de poder que está fundado en [...] la raza. La raza es ahora asociada a muchas cosas, a la etnicidad, a la nación estado, a la idea de género"4.

Para contrarrestar la colonialidad hay que darse cuenta de ella, "entender que el racismo se forma como núcleo central de la subjetividad de la especie" entendemos la vida y a nosotras/os mismas/os viviendo en ella, en el modo de conocer, de vivir, de pensar, de mirar, y a partir de allí, descolonizarse significa darse cuenta y cambiar hacia la construcción de la propia subjetividad con autonomía y plena conciencia. La decolonialidad o descolonialidad ${ }^{6}$ del poder, en este sentido, "es un proceso de cambio, igualmente específico [...] No puede ocurrir el cambio solo en las instituciones o por medios violentos, sino en el lavado de la subjetividad de toda la especie"7.

A partir de estas ideas, a principio de siglo XXI, un grupo de investigadores latinoamericanos se asocian para realizar un conjunto de estudios sobre la naturaleza de la modernidad y de la colonialidad, dando origen al denominado giro decolonia/ ${ }^{8}$, una especial articulación, diálogo y puntos de comunicación entre diversas perspectivas: el sistema mundo, los estudios culturales y postcoloniales, además del bagaje de todo el pensamiento crítico latinoamericano, en el cual investigadores/as como Enrique Dussel, Aníbal Quijano, Walter Mignolo, Sylvia Wynters, Edgardo Lander, Nelson Maldonado Torres, Catherine Walsh, Santiago Castro-Gómez, Ramón Grosfoguel, entre muchos otros/as, han realizado un gran trabajo intelectual.

La descolonialidad desde el feminismo fue propuesta por la filósofa argentina María Lugones, teórica y activista del movimiento de mujeres negras y parte del Proyecto ColonialidadModernidad-Descolonialidad, influida por el pensamiento feminista afroamericano, y en discusión con la propuesta de Quijano llega a la idea de colonialidad del género. Posteriormente, otras latinoamericanas activistas de diversos feminismos se le fueron uniendo.

\section{Feminismos descoloniales en América Latina: diferencias y articulación con otras formas de feminismo}

Los feminismos descoloniales nacen, como todo el pensamiento descolonial, proponiendo

\footnotetext{
4 QUIJANO, Aníbal, Conferencia La colonialidad /descolonialidad del poder, CLACSO en LASA, CLACSO TV, 2015 : https://www.youtube.com/watch?v=UhQU4HtGDpY\&t=2131s [Consultado 11 enero 2018]

5 Ibídem.

6 La mayoría de los autores/as de esta corriente de pensamiento utilizan indistintamente la palabra decolonial, que proviene del inglés decoloniality y descolonial; no obstante, Catherine Walsh dice preferir la supresión de la "s" para distinguirlo del significado en castellano "des", en tanto no se busca superar lo colonial sino transcenderla, construir una alternativa de pensar y estar en el mundo de una manera distinta a la determinada hegemónicamente por la cultura occidental. WALSH, Catherine. Interculturalidad, Estado Sociedad: Luchas (de) coloniales de Nuestra época, Universidad Andina Simón Bolívar, Ediciones Abya-Yala, Quito, 2009, pp. 15-16. RESTREPO, Eduardo, Rojas, Axel, Inflexión decolonial: fuentes, conceptos y cuestionamientos, Colección Política de la Alteridad, IESCP, Universidad Javeriana, Editorial de la Universidad del Cauca, Popayán-Colombia, 2010.

7 QUIJANO, Aníbal, op.cit.

8 CASTRO-GÓMEZ, Santiago, GROSFOgUEL, Ramón, (Ed.) El Giro Decolonial. Reflexiones para una diversidad epistémica más allá del capitalismo, Siglo del Hombre Editores, Bogotá, 2007.
} 
una relectura de la historia de Abya Yala9 (continente americano) desde 1492, según la cual la modernidad occidental nació gracias al capitalismo que se instaló a partir de ese momento, el colonialismo fue central para generar la modernidad occidental. Desde allí, se proponen otros marcos analíticos para la comprensión de las relaciones sociales, mediante una mirada imbricada de las opresiones de raza, sexo, clases, sexualidad y geopolítica ${ }^{10}$, que el capitalismo, el racismo y patriarcalismo origina en las vidas de las mujeres de la periferia en particular, y en las poblaciones de la periferia global en general ${ }^{11}$.

Los feminismos descoloniales desde el punto de vista epistémico y práctico se configuran como una crítica al interior del propio movimiento feminista, al cual terminan denominando feminismo hegemónico ${ }^{12}$, denunciando la manera universal de pensar la subordinación de las mujeres, dejando en claro que "no existe una mujer universal"13 y cuestionando la categoría de género. Entre sus principales exponentes se encuentran María Lugones, Yuderkys Espinosa y Ochy Curiel, Karina Ochoa, Gladys Tzul Tzul, Aura Cumes y Julieta Paredes, entre muchas otras. Aunque toma reflexiones que se han generado desde los feminismos postcoloniales, los feminismos negros, los feminismos autónomos, los feminismos críticos, los feminismos comunitarios e indígenas se han ido configurando como una forma de pensar y actuar con características propias.

Se diferencia del pensamiento postcolonial en que este último se generó en la India, sureste asiático y África (árabe y subsahariana) a partir del proceso de descolonización posterior a la II Guerra Mundial, durante las décadas de 1950 y 1960, el cual tiene en su haber los Ilamados estudios subalternos fundados por Ranajit Guha y los estudios postcoloniales con Edward Said, y sus interlocutoras feministas Gayatri Chakravorty Spivak ${ }^{14}$ y Chandra

9 Abya Yala, nombre con el cual los Kunas de Panamá denominaban al continente americano antes de la conquista europea, por consenso, actualmente, es el nombre adoptado por las comunidades indígenas.

${ }^{10}$ La geopolítica es central en el pensamiento descolonial, pues esta se entiende más allá de su connotación territorial, incluye la geocultura, en la cual se articulan la historia, el cuerpo/genero/sexo, la lengua, la religión, los conocimientos epistémicos/ontológicos, las jerarquías raciales. Determina las relaciones de poder/resistencia que se establecen entre colonizadores y colonizados a lo largo de la historia como estrategia de dominación por un lado, y de liberación/descolonización por otro.

${ }^{11}$ CURIEL, Ochy, Conferencia Feminismo decolonial latinoamericano y caribeño. Aportes para las prácticas políticas transformadoras, CICODE, Universidad de Granada, 7 de noviembre de 2016: https://www.youtube.com/ watch? $v=B 0 v$ LIIncsg0\&t=3172s [Consultado 18 diciembre 2017].

12 Los feminismos hegemónicos, en plural porque no son homogéneos ni en sus objetivos, intereses y análisis, son aquellos feminismos que aunque inicialmente enarbolaron las banderas de la libertad y de la igualdad de las mujeres ante los hombres, cayeron en la trampa del etnocentrismo o eurocentrismo propio de las ideologías de la modernidad (Liberalismo, Socialismo/Marxismo, Cristianismo, Conservadurismo y Colonialidad) y les fue imposible ver las luchas de las mujeres fuera de esos marcos epistemológicos; muchos de ellos quedaron subsumidos en el mainstream de género institucionalizado en lo internacional o en lo nacional bajo el esquema de políticas de igualdad de género asumiendo una postura de salvación de las otras mujeres, universalizando sus propuestas e ignorando que no siempre se ajustan a las realidades históricas, culturales y a las cosmovisiones de la diversidad de mujeres que existen. MEDINA, Rocío, "Feminismos periféricos, feminismos-otros: una genealogía feminista decolonial por reivindicar" en Revista Internacional de Pensamiento Político, I Época, vol. 8, 2013, pp. 53-79. Este tipo de feminismo es descrito como privilegiado/blanco/occidental/urbano/clase media/ universitaria/académica. A este feminismo Ochy Curiel le llama feminismo blanco, no necesariamente por el color de la piel, sino también por la ideología que le otorga un privilegio racial, de clase, de sexualidad y de geopolítica.

13 María Lugones enfatiza esta idea de la mujer como un ser no universalizable.

${ }^{14}$ La idea de subalterno se refiere a una situación, no a una identidad, es un sujeto sin voz, no porque no tenga la capacidad vocal, sino porque no es escuchado, su discurso no está validado por las instituciones modernas occidentales, que se han encargado no solo de silenciar sus voces, desechar la escucha y menospreciar sus saberes. De allí la idea de violencia epistémica mediante la cual desde occidente se abrogan la autoridad de hablar por el otro, el silenciado. De acuerdo con este planteamiento, en el caso de la mujer es imposible recuperar 
Talpade Mohanty ${ }^{15}$, entre otras, las cuales muestran desde el giro lingüístico la invisibilización del otro no occidental en un silenciamiento estructural dentro de la narrativa histórica, en la cual el sujeto válido es occidental. Spivak acuña la idea de violencia epistémica y Mohanty la de colonialismo discursivo. Planteamiento similar hace Edgardo Lander con su idea de colonialidad del saber, pero en clave descolonial ${ }^{16}$.

Además, develan que el patriarcado no es la única opresión que sufren las mujeres, que el género está racializado y la raza siempre es generizada, por lo tanto, muestran la subalternización, visualizan, igualmente, las formas de resistencia individual y colectiva ante la dominación. Pero también revelan la superioridad construida de la mujer occidental que sirve de modelo a las otras mujeres, las no occidentales.

Así, los feminismos descoloniales hacen una relectura de la historia ${ }^{17}$ de la región en particular y de la historia universal en general a partir de 1492, para pensarla no ya desde la historiografía hegemónica, en cuya narrativa el colonizador fue presentado como el conquistador y el descubridor que trajo la civilización, sino desde el punto de vista de las/ los colonizadas/os, desde las historias no contadas, silenciadas y olvidadas. Y a partir de allí mostrar que el primer genocidio de la historia humana se cometió en Abya Yala, y que esto aun tiene secuelas expresadas en la colonialidad contemporánea, a través de la llamada herida colonia/ ${ }^{18}$.

Los feminismos latinoamericanos estuvieron en sus orígenes influidos por los feminismos de Europa y EEUU, por lo que nacen con una carga teórica y práctica etnocéntrica. Algunas feministas fueron influidas por el liberalismo, la izquierda, las anarquistas, por ello emerge un feminismo autónomo ${ }^{19}$ a partir de los años de 1980 y 1990 que discute la necesidad de ser libre de los cánones tradicionales y nuevos de opresión, anteponiéndose a las feministas institucionales ${ }^{20}$; su crítica se dirige al feminismo relacionado con los partidos políticos, las ONGs, especialistas de género, de las políticas sociales del estado, que terminan

la voz, porque no se le ha concedido una condición de sujeto desde el cual hablar. SPIVAK, Gayatri Chakravorty ¿Puede hablar el subalterno? en Orbis Tertius, año 3, No 6, 1998, pp. 175-23: http://www.fuentesmemoria. fahce.unlp.edu.ar/art_revistas/pr.2732/p r.2732.pdf [Consultado 14 enero de 2018].

15 Propone un proyecto político e intelectual para los feminismos del Tercer Mundo deconstruyendo la producción del feminismo occidental sobre la mujer, en el que predomina el discurso sistemáticamente homogeneizante. MOHANTY, Chandra, "Bajo los ojos de occidente. Academia Feminista y discurso colonial" en SUÁREZ NAVAZ, Liliana, HERNÁNDEZ, Aída (Ed.), Descolonizando el Feminismo: Teorías y Prácticas desde los Márgenes, Editorial Cátedra, Madrid, 2008.

${ }^{16}$ Expresa la manera en que el conocimiento eurocéntrico se mantiene, propaga y reproduce como única forma de conocer, obviando otras formas de producción de conocimiento. LANDER, Edgardo (Ed.), La colonialidad del saber: eurocentrismo y ciencias sociales: perspectivas latinoamericanas, CLACSO, UNESCO, Buenos Aires, 2003.

17 Quijano lo denomina "otro horizonte de sentido histórico".

${ }^{18}$ Concepto que deviene de los escritos literarios de la feminista lésbica chicana Gloria Anzaldúa y que Walter Mignolo rescata, retoma e incorpora al pensamiento descolonial. MEDINA MARTÍN, Rocío, Op.cit., p. 61.

${ }^{19}$ El concepto de autonomía ha tenido siempre en América Latina una carga valorativa de gran importancia durante su historia política y en la historia de las ideas.

20 Vinculadas a los financiamientos provenientes del sstado y organizaciones financieras internacionales con quienes definen sus políticas, siguiendo las agendas establecidas por la ONU, son feministas que terminaron cooptadas, privilegiadas en sus posiciones de expertas en temas de género, salud reproductiva, derechos reproductivos y sexuales, violencia y derechos humanos. No obstante, a pesar de la crítica válida que siempre debe existir para no desviar los objetivos del feminismo, no se debe ni puede desmeritar los logros alcanzados por las feministas institucionales. 
subordinando a las mujeres a sus normativas, directrices y presupuestos. Significó un proceso de neocolonización y neodesarrollismo venido del norte occidental que encontró complicidad en las feministas de la región ${ }^{21}$. Proponen desmarcarse con la auto-organización, autofinanciación y despartidización.

Los feminismos descoloniales extraen de las autónomas esa necesidad de autoorganización, autogestión, crítica a la institucionalización y a la cooperación internacional. Estas estrategias permitirían garantizar que las prácticas políticas del movimiento no fueran dependientes de instancias que reproducen la colonialidad. Mientras, desde los feminismos indígenas ${ }^{22}$ se plantea el problema de las cosmovisiones de algunas comunidades que no son consideradas válidas por el etnocentrismo, pero que pueden ayudar a comprender la subordinación y emancipación de las mujeres del patriarcado23.

Adriana Guzmán (Bolivia), desde un feminismo muy cercano al feminismo indígena, el feminismo comunitario, sostiene "nosotras proponemos el feminismo comunitario como una teoría social, como una herramienta de lucha"24, en rebeldía ante un feminismo occidental que ven y sienten como un mecanismo de dominación, que impone qué es el feminismo y cómo ser una feminista, mostrándolo como algo ya establecido que no se puede repensar.

Julieta Paredes (Bolivia) sostiene que no se está pidiendo inclusión en el sistema occidental, ni el neoliberal ni el socialista, lo que se quiere es subvertir todas las formas de opresión, y en este afán han reconceptualizado las ideas de feminismo y patriarcalismo. Así el feminismo viene a ser "la lucha de cualquier mujer, en cualquier parte del mundo y en cualquier tiempo de la historia que lucha, se rebela y propone ante un patriarcado que la oprime o la pretende oprimir"25 de tal manera que el feminismo no nace con la Revolución francesa. Mientras que entienden por patriarcalismo "el sistema de todas las opresiones, todas las discriminaciones, todas las violencias que vive la humanidad"26 incluyendo la naturaleza.

Los feminismos descoloniales se proponen visibilizar las opresiones imbricadas, desmontar la adscripción epistemológica categorial de occidente, llaman a la desobediencia epistémica, a reevaluar el ethos civilizatorio occidental tanto en lo académico como en lo político y en la existencia misma. Invitan a pensar y a mirar de forma imbricada esas opresiones sociales, con un conocimiento situado, para proponer prácticas políticas más acordes a los

${ }^{21}$ CURIEL, Ochy, Conferencia Los aportes de las mujeres afro: De la identidad a la imbricación de las opresiones. Un análisis decolonial, Canal Facultad de Ciencias Sociales de la Universidad de Chile, 8 septiembre 2014: https://www.youtube.com/watch?v=IE_3ygwasHI\&t=630s [Consultado 5 de enero de 2018].

22 Se utiliza el término feminismos indígenas en el sentido expuesto por Julieta Paredes: "Toda acción organizada por las mujeres indígenas en beneficio de una buena vida para todas las mujeres, se traduce al castellano como feminismo", aunque consciente de que todos los términos relativos a los pueblos originarios de América son problemáticos y complejos. Existen pueblos nativos americanos que se niegan a ser llamados indígenas. GARGALLO, Francesca, Feminismos desde Abya Yala. Ideas y Proposiciones de las mujeres de 607 pueblos en Nuestra América, Editorial Corte y Confección, México, 2014.

${ }^{23}$ Aura Cumes (Guatemala) habla del patriarcado colonial y Lorena Cabnal (Guatemala) del patriarcado originario, uno anterior al patriarcado colonial, el cual hizo un entronque con el patriarcalismo occidental.

${ }^{24}$ GUZMÁN, Adriana, PAREDES, Julieta, Entrevista sobre Feminismo Comunal en Chiapas, en abril de 2014: https:// www.youtube.com/watch?v=C6I2BnFCsyk\&t=1212s [Consultado 02 de enero 2018].

${ }^{25}$ Ibídem.

${ }^{26}$ Ibíd. 
problemas, a las condiciones de acceso a los bienes materiales y simbólicos.

El pensamiento feminista descolonial latinoamericano no es homogéneo, es divergente y heterogéneo, tiene diversos lugares de enunciación, en los que se alejan, se acerca, o entrecruzan planteamientos y prácticas, pero siempre en diálogo. Parten de supuestos comunes, pero no pretenden enarbolar un solo discurso descolonial porque eso sería crear un nuevo universalismo, un nuevo pensamiento hegemónico que determinaría lo verdadero y lo válido.

\section{Concepciones ontológicas, epistemológicas, estéticas y éticas desde el feminismo descolonial}

\subsection{Ontología política de la dominación}

Ontología política de dominación es un concepto del cual parte la feminista/activista mexicana Karina Ochoa para identificar la ontología moderna basada en la tradición racionalista que se inicia con René Descartes en el siglo XVII, pero que se convierte en la única forma de existencia posible, por tanto, única forma de organización del orden social de la humanidad, basado en los criterios de secularización, dualismo ontológico, de un yo pienso luego existo27, universalismo, objetividad científica como neutralidad, el individuo como centro del mundo.

La ontología política de la dominación es la "rama de la filosofía que estudia la naturaleza del ser, de la existencia y de lo real" y permite entender cómo se constituye ese ser, su existencia y su experiencia vivida. Esta categoría posibilita comprender el problema de las poblaciones originarias de Abya Yala, con una historia/existencia asociada al sometimiento que les dejó en el lugar de las periferias con respecto a la centralidad de los colonizadores. Explica la manera como a las personas originarias de Abya Yala se le configuró en india/o, quitándoles la posibilidad de autonombrarse, nombrándolas, cómo le quitaron la posibilidad de su existencia y le impusieron como única forma posible la occidental, único horizonte de ser, estar y existir en el mundo.

Los teólogos del siglo XVI y las denominadas Controversia de Valladolid de 1550 entre Juan Ginés de Sepúlveda ${ }^{28}$ y Bartolomé de las Casas sentaron los principios que normaron la vida del mundo moderno y mostraron los fundamentos ideológicos sobre los que se sustenta la desigualdad y la subordinación que han impedido a las/los indígenas incursionar como sujetas/os plenas/os de derecho en el ámbito político, pero también a las poblaciones emanadas de las excolonias. La retórica moderna de la salvación y la civilización en función de la lógica de la dominación y la opresión.

De esta manera, de acuerdo con Ochoa, se procedió a la feminización del indio en

\footnotetext{
${ }^{27}$ Enrique Dussel cuestiona ese yo pienso, luego existo (ego cogito ergo sum) y establece que antes del yo pienso está el yo conquisto (ego conquiro ergo sum). Mignolo dice "soy donde pienso" indicando el lugar de enunciación.

28 Juan Ginés de Sepúlveda, de influencia Aristotélica, es de acuerdo con los planteamientos de Karina Ochoa uno de los padres del discurso moderno del Derecho Internacional, sino también uno de los teólogos precursores del discurso de la modernidad. OCHOA, Karina, Ontología de la dominación. Una perspectiva desde los feminismos descoloniales, Sesión 2, 15 de agosto de 2017: https://www.youtube.com/watch?v=zgQIjQYoF7o [Consultado 15 de agosto de 2017].
} 
tanto quedó subordinado al hombre-blanco-europeo y se le asemejó al infante y a la mujer; quienes debían estar tutelados, se convirtieron en sujetas/os no plenas/os. En este sentido la discusión no es su humanidad, sino su incapacidad para gobernarse y administrar bienes. En el caso de las personas esclavizadas, la situación se empeora porque fueron despojadas completamente de su humanidad, bestializadas y por tanto anuladas como seres, convertidas en no seres en razón de la raza, siendo así la primera vez en la historia que la esclavitud se asocia con negritud. Ahora bien, cuando se crea el estado nación liberal, y se incorpora el positivismo, la ecuación sigue basada en condiciones de inferioridad racializada, pero agregándoles nuevos ingredientes, en este caso tener o poseer bienes, educación o saber, de tal forma que para ser habría que tener y saber.

De acuerdo con Ramón Grosfoguel ${ }^{29}$, el racismo instaurado se convirtió en un racismo institucional y estructural que es mucho más grave que el racismo individual, porque no se agota en los prejuicios y estereotipos, sino que privilegia a unos y pauperiza a otros grupos, cuestión que impide las alianzas políticas de los grupos. Así, aunque el indígena queda en condición de inferioridad, por debajo de él queda el negro africano, pero más abajo de todos estos inferiorizados queda la mujer (indígena y negra). Se construyen estructuras racistas y patriarcales en el plano de la epistemología moderna que inferioriza las epistemologías distintas, inferioriza las/os sujeta/os indígenas y africanas/os y sus conocimientos, al privilegiar la del hombre occidental. "La descalificación epistémica se convierte en un instrumento privilegiado de la negación ontológica o de la sub-alterización. "Otros no piensan, luego no son"'"30.

La ontología es anterior a la epistemología, es el telón de fondo de esta, determina quiénes son seres humanos, quiénes tienen derecho a qué cosa y a qué no. Descolonizar la ontología remite a comprender que existen otras ontologías que son pluridiversas, es decir, una diversidad de existencias en este mundo, el mandar obedeciendo zapatista, el buen vivir de la tradición andina, el sentí-pensar de los pueblos de Chiapas, la filosofía del nosotros de la tradición maya, por nombrar algunas que Karina Ochoa y otras feministas recuerdan que existen.

\subsection{Epistemología feminista descolonial}

La epistemología feminista descolonial surge de las prácticas políticas de las mujeres negras, indias, latinas, lesbianas y autónomas que se sintieron marginadas por un pensamiento feminista occidentalizado que no daba cuenta de sus realidades y vivencias. De tal forma, María Lugones pone en cuestión lo sostenido por Quijano acerca de la colonialidad, al entender que este no profundiza en el tema de la discriminación racial, social y existencial de la mujer en las relaciones entre sexos, lo acusa de mantener una visión biologicista.

Lugones propone el concepto de sistema de género moderno, que explica cómo la colonización estableció un régimen epistémico basado en una jerarquización dicotómica entre lo humano y lo no humano, del cual luego se desprenden categorías de diferenciación racial

\footnotetext{
${ }^{29}$ GROSFOGUEL, Ramón, OCHO, Karina, Seminario Transculturalidad, Sesión 1, GLEFAS/UNAM: https://www. youtube.com/watch?v=PD2MrP5_0U4\&t=3913s [Consultado 11 de febrero de 2018].

30 MALDONADO TORRES, Nelson, "Sobre la colonialidad del ser: contribuciones al desarrollo del concepto", 2004, p.145: http://www.decolonialtranslation.com/espanol/maldonado-colonialidad-del-ser.pdf [Consultado 15 de febrero de 2018].
} 
y de género. En el proceso de deshumanización se produce una subjetificación, en clave foucaultiana, que gracias a la subjetividad activa (agencia mínima ${ }^{31}$ ) es resistida en una estrategia de supervivencia, de rebeldía y de oposición a la subalternización desde la infrapolítica colectiva e individual.

Lugones le otorga al género el mismo poder explicativo que Quijano le otorga a la raza, por tanto, raza y género se convierten en categorías inseparables para entender las opresiones de las mujeres. Propone hacer una relectura de la modernidad capitalista colonial, en tanto que "La imposición colonial de género atraviesa cuestiones de ecología, economía, gobierno, relaciones con el mundo espiritual, y saberes, a la vez que prácticas cotidianas que o nos habitúan a cuidar el mundo o a destruirlo"32.

Desde el concepto de interseccionalidad ${ }^{33}$ muestra las múltiples opresiones que las mujeres negras estadounidenses comprendieron en su experiencia de relacionamiento con mujeres blancas y con hombres de su comunidad y analiza cómo esa interseccionalidad de raza/género/clase/sexualidad/edad/ubicación geopolítica son inseparables, pone de manifiesto las opresiones que viven las mujeres de color, las mujeres-otras que sufren la violencia de la colonialidad del género, violencia que ejercen el estado, el patriarcado blanco occidental y los hombres que viven bajo la dominación racial.

El sistema colonial de género tiene un lado visible y uno oculto; el visible es el que construye hegemónicamente al género, y el lado invisible es el que oculta la crueldad hacia la otredad. Sueli Carneiro, feminista/activista brasileña, recuerda que la división sexual de los ámbitos privado y público no podían aplicarse a las experiencias vividas por las mujeres afrodescendientes: "Somos [...] mujeres que [trabajaron] durante siglos como esclavas, labrando la tierra o en las calles vendiendo o prostituyéndose [...] que no entendían nada cuando las feministas decían que las mujeres debían ganar las calles y trabajar! Somos parte de un contingente con identidad de objeto" ${ }^{\prime \prime}$.

Cumes señala en conexión con Yuderkys Espinosa, que la epistemología que está detrás del feminismo hegemónico blanco es el que considera a Europa como inicio y fin de la historia y eso además de ser un problema ontológico y epistemológico es también político, pues se hacen eco de la idea de que los pueblos indígenas no tienen un pasado digno de recordar, epistemologías dignas de tener en cuenta como horizonte político, porque al haber sido bestializados, al igual que los animales, no son capaces de crear ni cultura ni sociedad.

${ }^{31}$ La subjetividad activa es una categoría que utiliza Lugones para señalar un tipo de agencia mínima desde la cual opera el acto de resistir a la deshumanización, a pesar de no contar con voz, con legitimidad. Equivale a tener consciencia de estar oprimida/o pero no vencida/o. LUGONES, María, "Hacia un feminismo descolonial" en La Manzana de la Discordia, n², vol. 6, julio-diciembre, 2011, p.p. 105-119.

32 Ibíd., p.106.

${ }^{33}$ Interseccionalidad viene a ser el punto donde se cruzan las opresiones con las diferentes identidades de una persona. Los antecedentes del concepto se encuentran en el discurso pronunciado en 1851 ante convención por los derechos de las mujeres en Akron, Ohio, por Sojourner Truth (ex-esclava) y en las propuestas de las activistas negras y chicanas estadounidenses durante la segunda década del siglo XX, Angela Davis, Audre Lorde, Bell Hooks, June Jordan, Gloria Anzaldúa, entre otras, así como en el manifiestos de las Colectivas del Río Combahee (1977). BRAH, Avtar, PHOENIX, Ann, "Ain't I a Woman? Revisiting intersectionality", Journal of International Women's Studies, vol 5 n³, 2004, pp. 75-86.

${ }^{34}$ CARNEIRO, Sueli,"Ennegrecer el feminismo": http://www.bivipas.unal.edu.co/jspui/bitstream/10720/644/1/264Sueli\%20Carneiro.pdf [Consultado 05 de enero de 2018]. 
Es, por tanto, "una episteme que se encuentra en las mentes, los corazones y los cuerpos de las mujeres que habitan con nosotras, con quienes habitamos juntas estas geografías" 35 .

La propuesta feminista descolonial es la de generar lo que Quijano denominó una revolución epistémica ${ }^{36}$, desde la cual se revisa, se cuestiona, se critica y también se reconocen los aportes de las feministas hegemónicas, pero nombrando todo aquello que estas dejaron de nombrar, lo que quedó en la exterioridad, lo que no podían mirar por no formar esto parte de sus propias experiencias; haciéndolo desde una situación dialogante de las diversas experiencias de intelectuales y de activistas comprometidas con un pensamiento no eurocéntrico, un diálogo horizontal, situado, sin pretensiones de universalización ni de verdades absolutas, sin pretendidas objetividades, que muestre el lugar de enunciación y se opongan al método científico clásico, pero de manera propositiva.

\subsection{De la estética moderna a la aesthesis descolonial}

Descolonizar la estética significa liberar la aesthesis oculta en esta, en tanto la aesthesis ${ }^{37}$ se refiere más a los sentidos que al pensar, lo no racional, la sensibilidad. Requiere mostrar cómo la retórica de la modernidad señaló el horizonte esperado en la estética, lo que se debe sentir y percibir como bello, en una lógica de negación, de ocultamiento y de opresión de otras maneras de sentir y percibir. Desde el feminismo decolonial pensar la aesthesis significa ir más allá del arte ${ }^{38}$, en el cual el arte se circunscribe a lo hecho dentro del canon occidental, el resto es folklore, tradición a lo sumo, e intentar relacionarlo con el racismo y el sexismo, quién es la mujer bella, la que fue designada como mujer; las racializadas no son mujeres, por tanto tampoco son bellas, son cuerpos sexualizados, tocables, violables, pero no bellos.

El canon de belleza se va modificando con la época, pero este desde la colonia ha sido eurocéntrico/etnocéntrico, pues los valores e ideas dominantes de cada momento histórico son los valores de la clase dominante. Durante el siglo XX, en la década de 1990, Naomi Wolf en el libro El mito de la belleza alertaba cómo el patriarcado se había valido mediante la industria mediática para capitalizar las luchas feministas de liberación y sujetarlas a un nuevo corsé de dominación mediante la cosificación y la hipersexualización con "imágenes de belleza inflexibles y crueles [...], efímeras e interminables, inalcanzables" ${ }^{\prime 39}$, que pesan sobre los rostros y cuerpos desvalorizándolos y aniquilando su autovaloración y con ello su empoderamiento. Sentencia: "La belleza no es universal ni inmutable, aunque occidente pretenda derivar todos los ideales de belleza femenina en una especie de idea platónica"40.

\footnotetext{
${ }^{35}$ CUMES, Aura, 1er Coloquio Internacional sobre Transculturalidad Pensamiento y Estética Descoloniales, GLEFAS/ UNAM, 8 al 10 de febrero de 2016: https://www.youtube.com/watch?v=zfpuLJDO-Qc [Consultado 05 de enero de 2018]

36 Uno de los tantos problemas epistemológicos que enfrentan los feminismos descoloniales son la no validación de los aportes teóricos de las feministas en las universidades occidentales y occidentalizadas, incluso Yuderkys Espinosa se queja de que las feministas latinoamericanas no se citan entre sí, citan solo a las validadas por la academia.

37 Palabra que proviene del griego y cuyos significados son sensación visual, auditiva o gustativa, proceso de percepción.

${ }^{38}$ Por razones de espacio no se adentra en el tema del arte, sino de lo considerado bello físicamente. No obstante, existen estudio que revelan la marginación de las mujeres como artistas que merecen ser revisados y trabajados en futuras investigaciones.

39 WOLF, Naomi, "El mito de la belleza", Editado William Morrow and Co., 1991, p. 214.

${ }^{40}$ Ibídem, p. 217.
} 
El avance en las tecnologías de comunicación con todo su poder socializador permite el bombardeo de estas imágenes estandarizadas de lo bello, los concursos de belleza, la cinematografía, la fotografía, las revistas de modas, la moda, los programas de televisión, los reality show, videoclips, entre otros, son canales por los cuales se afecta la imagen de sí misma que tienen las mujeres occidentales/occidentalizadas/racializadas, de manera despectiva y degradante si no logran ajustarse al canon de belleza establecido. Las convierten en enemigas/competidoras, banalizan la vida y ensanchan la vanidad, generando el autoodio, de manera que su atención se centra en su aspecto exterior, en la preocupación por no envejecer, no engordar, en no mostrar imperfección corporal y dejar de gustar, en lugar de ocuparse de su autorealización como ser libre.

El modelo estandarizado de belleza femenina está asociado con rasgos caucásicos, mientras todo lo que no se ajuste al estándar es considerado feo; así una mujer indígena, negra, pobre, campesina, envejecida, no puede ser considerada bella. Tampoco la feminista, ser feminista es ser fea para los detractores del movimiento. Entonces, la forma de alcanzar este ideal irrealizable y antinatural es reconstruirse mediante la industria de la llamada cirugía estética y cosmética, hacer dietas insalubres, el gimnasio, vestir a la moda, usar ciertas marcas de ropa, lo cual requiere una dinámica de consumo que solo algunas privilegiadas pueden concederse y las no privilegiadas tratan de imitar dentro de sus posibilidades.

Descolonizar la estética, además de liberar la aethesis, pasa por hacer las paces con el propio cuerpo y aspecto y darse cuenta de que detrás de la insatisfacción hacia sí misma hay toda una maquinaria totalizante de poder racista, deshumanizante que hay que desenmascarar, porque detrás de una belleza dominante hay una belleza dominada. La metáfora del cuerpo femenino de sensualidad y éxito, en la práctica, paradójicamente, se transforma en el poder del hombre que la posea, porque el cuerpo pasó a ser mercancía deseable. Es necesario liberar el cuerpo ${ }^{41}$ y tener una nueva posibilidad de estar y ser en el mundo.

La idea de belleza es heterogénea como heterogéneo es el ser humano, es personal y única, depende de lo que conmueve, de lo que convoque o provoque en el otro y en sí mismo, el que admira y es admirado, el que observa y es observado; es subjetivo, no puede ser universal, aunque puede ser respetuosamente dialogante.

\section{4. Ética vista desde la descolonialidad}

La ética descolonial emerge de los estudios realizados por Enrique Dussel ${ }^{42}$ sobre los trabajos de Emmanuel Levinas acerca del humanismo semita, el cual parte de la proximidad originaria del/la sujeto/a ante el/la otro/a experimentada/o como persona; en el cara-a-cara ético, anterior a toda otra relación, es muy diferente del/la sujeto/a-objeto desde donde se construye el suelo ontológico de la ética moderna. Explica Dussel "[...] la primera experiencia del feto

\footnotetext{
${ }^{41}$ Hablar de cuerpo remite a un sinnúmero de concepciones, conocimientos y experiencias: el cuerpo productivo y el reproductivo, el performance, la biología, la genética, el del/la niño(a), del/la anciano (a), el de la sexualidad, del placer y el goce, también de los cuerpos en desobediencia, los queer, los trans, los anoréxicos, los obesos, los mutilados, los torturados, los enfermos, los estériles, los desnutridos, los de la lógica del mercado y de la hegemonía de la tecnología que reproducen el narcisismo vacío y mediático. LOYDEN SOSA, Humbelina, SÁNCHEZ BRINGAS, Ángeles, "Cuerpo" en GAMBOA, Susana Beatriz, (Coord) Diccionario de Estudios de Género y Feminismos, Ediciones Biblos, 2da Ed. [1era. Ed. 2007], 2009, pp.74-77.

42 DUSSEL, Enrique, "Humanistes d'América: 14 Tesis d'Ética", Conferencia Magistral en Casa América Catalunya: https://www.youtube.com/watch?v=kyqnJWK_IFI\&t=4990s [Consultado 10 de noviembre 2017].
} 
es vivir por dentro del cuerpo de su madre, [...] y cuando nace es acogido en las manos de alguien, y cuando come, come alguien no algo, podemos decir la relación sujeto/sujeto es la primera relación $[\ldots]^{\prime \prime 43}$.

En este sentido, durante la conquista, el colonizador no actuó desde sus estándares éticos de vida, sino desde la no-ética, "la excepcionalidad [ética] era mostrada por la forma como los colonizadores se comportaban en relación con las poblaciones indígenas y las comunidades negras esclavizadas"44, lo cual se revela en el libro Mujeres, raza y clase de Angela Davis citado por María Cruz Tornay Márquez: "las mujeres esclavas [...] solo fueron vistas como 'madres' cuando se interrumpió el tráfico internacional de personas, los propietarios optaron por los criaderos de esclavos para asegurar la mano de obra en las plantaciones" 45 .

La experiencia del/la colonizado/a y la primera experiencia de la persona nacida esclava o sirvienta fue el sufrimiento, el dolor, el maltrato y la vida como algo indigno de ser vivido. En este sentido, el dilema ético que está planteado es lo que señalaba Freire en Pedagogía de la Esperanza: "No sería posible deshumanizar sin deshumanizarse [...]. No soy si tú no eres y, sobre todo, no soy si te prohíbo ser"46. "Hacer al mundo ético es una consecuencia necesaria de la producción de la existencia humana, o de extender la vida en existencia"47.

De este modo, la ética descolonial implica el deber de construir una existencia digna de ser vivida, por tanto, antirracista, antisexista, anticlasista, antipatriarcal, antihegemónica y ecologista. Así como la recuperación de la memoria histórica de las/os sujetas/os colonizadas/ os, la recuperación de sus voces, la supresión de todas las opresiones, presentar opciones teóricas y políticas que les permita recuperar la humanidad y la dignidad a los seres (mujeres y hombres, niñas/os, ancianas/os) que históricamente han sido inferiorizados por su raza, clase, sexo, nacionalidad, edad, pero primordialmente, sin estandarizar todas las opresiones porque como dice Lorena Cabnal "somos cuerpos diferentes, las emancipaciones son plurales"48.

\section{Prácticas políticas colectivas descoloniales y sus propuestas de transformación socio políticas}

Catherine Walsh, haciendo suyas las palabras de Stuart Hall, sostiene que "los momentos políticos producen movimientos teóricos" ${ }^{\prime 49}$, de allí que la experiencia genera teoría, pues las teorizaciones que desde la práctica y dentro de la lucha por transformar lo político, lo social,

${ }^{43}$ Ibídem.

${ }^{44}$ MALDONADO TORRES, Nelson, "Sobre la colonialidad del ser... op. cit., p.137 http://www.decolonialtranslation. com/espanol/maldonado-colonialidad-del-ser.pdf

45 TORNAY MÁRQUEZ, María Cruz, "Comunicación, decolonialidad y género: una crítica a los estudios de medios de comunicación de masas desde el feminismo decolonial" en SIERRA CABALLERO, Francisco, RIVERA MALDONADO, Claudia, (Coord.) Comunicación, Decolonialidad y Buen Vivir, Ediciones Ciespal, Ecuador, p. 212.

${ }^{46}$ FREIRE, Paulo, Pedagogía de la Esperanza, Siglo XXI, México, 1993, p.95.

47 FREIRE, Paulo, Pedagogy of Indignation, Paradigm, Boulder, Colorado, 2004, p. 98.

48 CABNAL, Lorena, "Feminismo comunitario, una propuesta epistémica, espiritual y política para aportar en la construcción plural de un mundo nuevo", Ciclo sobre Género y Desarrollo: Voces Femeninas del Sur, Universidad de Granada, 2015:https://www.youtube.com/watch?v=2dr3HT-tLtc\&t=1238s [Consultado 21 de febrero de 2018].

49 WALSH, Catherine, "Introducción. Lo Pedagógico y lo Decolonial. Entretejiendo caminos" en WALSH, Catherine, (Ed.) Pedagogías decololoniales: Prácticas urgentes y resistir, (re) existir y (re) vivir, Serie Pensamiento decolonial, Tomo I, p. 23. 
lo cultural, en la búsqueda de construir caminos hacia un "estar, ser, pensar, mirar, escuchar, sentir y vivir con sentido u horizonte de(s)colonial"50 conlleven a lugares de emancipación y liberación de subjetividades.

En ese sentido, los movimientos de resistencia ${ }^{51}$ de los pueblos de Abya Yala y de los pueblos africanos implantados en estas tierras son claramente "estrategias, prácticas y metodologías-pedagogías- de lucha, rebeldía, cimarronaje, insurgencia, organización y acción" para desafiar la dominación impuesta por el colonizador "para seguir siendo, sintiendo, haciendo, pensando y viviendo -decolonialmente- a pesar del poder colonial"52. Estas formas de accionar fueron quedando en la memoria colectiva de estas comunidades/ pueblos como maneras de vivir, existir y ser veladamente en contraposición al esquema de dominación impuesto.

A pesar de la imposición por la fuerza, la fe y luego por la ciencia basada en una racionalidad binaria (civilizado/bárbaro, hombre/naturaleza, superior/inferior) fusionadas con las ideas de raza y género que establecieron jerarquizaciones y sistemas de poder por más de 500 años, estas poblaciones encontraron las maneras de resistir manteniendo sus memorias colectivas en algunos reductos poblacionales importantes. Algunas poblaciones indígenas lo hicieron mediante escritos como el Huarochirí y el Popol Vuh, y las poblaciones africanas a través de la oralidad y de mecanismos creativos que les permitieron transgredir la autoridad hegemónica de manera no visible.

Las feministas descoloniales en sus luchas han mantenido como constante en sus diversas experiencias y desde diversos lugares una práctica pedagógica, expresada en la estrecha "relación entre el hacer y el pensar, [...] del producir conocimiento que articula teoría y praxis" 53 para problematizar, ubicar y explicar las situaciones que viven las mujeres, las realidades de sus comunidades y sus lógicas de organización. Criticar de manera propositiva el sistema de colonialidad del género, reconocerse entre feministas diversas, con posturas diversas, pero con un punto en común, el ser feminista desde la periferia o desde los márgenes. Todas respondiendo a sus propias realidades y generando diálogos de saberes y escuchas que permiten ver los rasgos a descolonizar tanto visibles como no visibles.

Se ha generado una sinergia respetuosa entre intelectuales orgánicas, académicas y activistas, mostrando otras formas de teorizar, desestructurando las jerarquías tradicionales

\footnotetext{
50 Ibídem, p. 24.

${ }^{51}$ La resistencia es una forma de conducta de oposición o rebelión ante fuerzas impuestas sobre la vida del ser que le impiden el ejercicio de su propia libertad y pensar por sí misma, de tal manera que la memoria opera como una forma de resistencia, la literatura, la música, la danza, las ceremonias, la lengua, las creaciones populares, la autobiografía, la oralidad, los silencios, entre muchas otras, que operan como actos éticos, políticos, epistémicos, ontológicos, pedagógicos de emancipación, de reclamo de la voces silenciadas, y que emergen desde las periferias o los márgenes para no olvidar, pero también con la esperanza de cambiar el orden opresor en cualquier momento. Porque "Donde hay poder hay resistencias". FOUCAULT, Michael, Historia de la sexualidad I. La voluntad de saber, Siglo XXI, Buenos Aires, 1990, p.113. LUGONES, María, "Hacia un feminismo descolonial" op. cit. MIGNOLO, Walter, "Escribir por mandato y para a emancipación ¿descolonización?: autobiografías de resistencia y resistencia a la autobiografía" en ORBE, J. (Comp.) La situación autobiográfica, Corregidor, Buenos Aires.

52 WALSH, Catherine, (Ed.) Pedagogías decololoniales ... op. cit., p. 25.

${ }^{53}$ ESPINOSA, Yuderkys et. Al., "Reflexiones pedagógicas en torno al feminismo descolonial. Una conversa en cuatro voces" en WALSH, Catherine, (Ed.) Pedagogías...op. cit., p. 409.
} 
de producción de conocimiento, utilizando como metodología la experiencia y saberes acumulados por las comunidades, repensando las cosmovisiones, lo que significa ser un ser humano, la relación con la naturaleza, entendiendo que la descolonización no puede venir desde otras/os, sino desde sí misma/o.

\section{Pensamiento descolonial y Relaciones Internacionales}

El giro descolonial representa una crítica a la naturaleza de la modernidad y la colonialidad, por tanto, es subversivo del statu quo internacional; surge desde América Latina, pero sin invisibilizar a los otros sures ${ }^{54}$. Esta perspectiva permite visibilizar el racismo en el sistema internacional y analizarlo bajo el lente de la diferencia colonial y la diferencia imperia/55 para así explicar los comportamientos de quienes tienen el poder y de quienes se disputan ese poder. Por ello, tiene un importante potencial crítico para el análisis internacional actual.

El mundo contemporáneo se encuentra inmerso en una crisis civilizatoria ${ }^{56}$ y el llamado es a repensar sus supuestos. Se observa el peligroso resurgir de la supremacía blanca y con ello la mayor visibilización del racismo, ejemplificado en el ascenso al poder de personajes como Donald Trump, ${ }^{57}$ cuyo discurso racista no pretende ocultar, y de partidos de extrema derecha en Europa que asumen discursos similares, además del aumento de las políticas del muro implementada por Europa y EE.UU., es una muestra de que no es una anacronía hablar de racismo para analizar los comportamientos sociopolíticos de las personas, los estados y el sistema internacional.

Y esto se refleja cuando dentro del ordenamiento internacional no se le otorga el mismo tratamiento a las violaciones de los derechos humanos ${ }^{58}$ que cometen soldados estadounidenses en cualquier parte del mundo en nombre de la libertad con relación a los cometidos por otros ejércitos de otros estados considerados menos civilizados. O cuando no se le otorga a un presidente de origen indígena la misma dignidad que se le otorga a un presidente occidental u occidentalizado. Para el movimiento feminista descolonial, los derechos humanos no deben ser privilegios de unos cuantos, sino que deben ser parte de la humanidad y de la humanización del sistema internacional y para ello es menester hacer una revisión del concepto de humanidad.

Desde los feminismos descoloniales surge una fuerte crítica a la cooperación internacional como forma sutil de institucionalizar el movimiento feminista a través de la ONGeización, en

${ }^{54}$ Partiendo de la idea de la existencia de sures en el norte y nortes en el sur de todos los continentes, en el que el sur detenta la posición geopolítica y geocultural que se encuentra fuera de la línea del ser.

${ }^{55}$ Conceptos elaborados por Walter Mignolo para analizar las relaciones de poder sustentadas en la raza (superior/ inferior) que se establecen entre naciones que fueron colonizadas y naciones imperiales y entre naciones imperiales propiamente dichas, que se disputan la hegemonía mundial.

${ }^{56}$ En la actualidad el sistema internacional atraviesa por una crisis que se podría denominar multidimensional, en tanto confluyen la crisis económica-financiera, crisis de refugiados/migratoria, crisis humanitaria, cambio climático, crisis de seguridad, crisis de la democracia.

57 Detentor del liderazgo mundial, expresa de forma irrespetuosa su campaña antimigrantes, su actitud hacia América Latina y países como Haití y El Salvador (shithole countries), su agresiva política exterior de sanciones, aranceles y amenazas, apoyo al armamentismo, su antiecologismo, además de su actitud machista y misógina hacia las mujeres, es el ejemplo claro de un problema civilizatorio que pone en peligro al planeta en general.

${ }^{58}$ El 10 de septiembre de 2018 John Bolton, diplomático y asesor de Seguridad Nacional estadounidense, amenazó con sancionar a los jueces de la Corte Penal Internacional si estos abrían alguna investigación sobre crímenes de guerra cometidos por soldados estadounidenses en Afganistán durante 2003 y 2006. 
tanto la ONU, BM y FMI mediante la cooperación internacional estructuran y burocratizan las prácticas políticas, imponiendo las reglas del juego y manteniendo el patriarcalismo. Este tipo de dominación impele a los feminismos a encontrar caminos de autonomía evitando la dependencia de las subvenciones del estado o de los organismos internacionales, y negándose a ser tratadas como víctimas incapaces de lograr desarrollo. Se propone descolonizar el feminismo no solo desde la teoría, sino desde la ontología, la estética, la ética y la política, construyendo nuevas formas de relacionamiento desde la heterogeneidad con una actitud contrahegemónica.

El feminismo descolonial, al proponerse desmontar la adscripción categorial de occidente tanto en lo académico como en lo político, cobra vital importancia en y para las Relaciones Internacionales, en tanto que uno de los retos del pensamiento descolonial ha sido comprender la dimensión global y su conexión con lo local para repensar las posibles alternativas políticas al cambio climático, a los derechos humanos, a la globalización neoliberal y a la colonialidad y en ese sentido adquiere carácter geopolítico.

\section{Conclusiones}

El feminismo descolonial hace críticas severas a todas las formas de injusticia, pues entiende que al final de las jerarquizaciones en las que se sostiene este orden hay una mujer racializada, empobrecida y subestimada. Las feministas descoloniales sugieren diálogos horizontales y no más relacionamiento desde el privilegio masculino; no obstante, no pretende dar soluciones universales, porque solo es una opción, una invitación a ser/pensar/sentir y existir diferente a lo establecido como válido. Dice Mignolo que este pensamiento "no nos sirve para resolver el problema de Ucrania, del Estado Islámico, de España"59, pero permite a cada una/o darse cuenta del lugar que ocupa dentro de la matriz colonial y, una vez hecho esto, tener control de la propia subjetividad y plantearse sus propias estrategias. En tanto la descolonialidad da un instrumento de análisis que no se encuentra ni en el liberalismo, ni en el marxismo, ni en el islamismo fundamentalista, ni tampoco en las disciplinas de las ciencias sociales, puede ser innovador como teoría abarcadora de la disciplina internacional.

Aída Hernández propone como pistas para descolonizar: historizar y contextualizar las desigualdades de género, pensar la cultura como proceso histórico en contraposición a los esencialismos, luchar contra el colonialismo, el racismo, el neoliberalismo como elementos fundamentales para desestructurar el patriarcalismo, establecer los vínculos entre las luchas locales y los procesos globales, integrar la investigación y el activismo como coproducción de conocimientos y diálogo de saberes, entre otras ${ }^{60}$. Todo esto sin dejar de lado las protestas, las manifestaciones y las presiones al sistema ante las injusticias y la impunidad.

En ese sentido, es una propuesta profundamente geopolítica porque se sitúa corporal, histórica y territorialmente, va dirigida a aquellas/os que han estado en los márgenes y les invita a salirse de la lógica colonizate/universalizante (de poder, de saber y de género) y

\footnotetext{
59 MIGNOLO, Walter, Conferencia La opción decolonial y la actualidad mundial, CIDOC, 5 de marzo de 2015: https://www.youtube.com/watch?v=WibKFg98M_g [Consultado 07 de enero de 2018].

${ }^{60}$ HERNÁNDEZ, Aída, Conferencia presentada en el 1er Internacional sobre Transculturalidad, Pensamiento y Estéticas Descoloniales, UNAM, 2016: https://www.youtube.com/watch?v=0RHq8HDx7aQ [Consultado 13 de febrero de 2018].
} 
a considerar el valor de las epistemologías-otras, las éticas-otras, las estéticas-otras y las ontologías-otras para pensar y vivir desde una pluriversidad, construida desde la resistencia estratégica para confrontar los diversos tipos de violencias. Y quizás esto permitirá vislumbrar otros mundos posibles fuera del discurso único de derecha y de izquierda.

\section{Bibliografía}

BRAH, Avtar, PHOENIX, Ann, "Ain't I a Woman? Revisiting intersectionality", Journal of International Women's Studies, vol 5, n³, 2004, pp. 75-86.

CABNAL, Lorena, "Feminismo comunitario, una propuesta epistémica, espiritual y política para aportar en la construcción plural de un mundo nuevo", Ciclo sobre Género y Desarrollo: Voces Femeninas del Sur, Universidad de Granada, 2015:https://www.youtube.com/watch?v=2dr3HT-tLtc\&t=1238s [Consultado 21 de febrero de 2018].

CASTRO-GÓMEZ, Santiago, GROSFOGUEL, Ramón, (Ed.) El Giro Decolonial. Reflexiones para una diversidad epistémica más allá del capitalismo, Siglo del Hombre Editores, Bogotá, 2007.

CARNEIRO, Sueli,"Ennegrecer el feminismo": http://www.bivipas.unal.edu.co/jspui/ bitstream/10720/644/1/264-Sueli\%20Carneiro.pdf [Consultado 05 de enero de 2018].

CÉSAIRE, Aimé, "Discursos sobre la negritud. Negritud, etnicidad y culturas afroamericanas" en Discursos sobre el colonialismo, Ediciones Akal, 2007, pp.85-91.

CUMES, Aura, Conferencia presentada en 1er Coloquio Internacional sobre Transculturalidad Pensamiento y Estética Descoloniales, GLEFAS/UNAM, 8 al 10 de febrero de 2016: https://www.youtube. com/watch?v=zfpuLJDO-Qc [Consultado 05 de enero de 2018].

CURIEL, Ochy, Conferencia Los aportes de las mujeres afro: De la identidad a la imbricación de las opresiones. Un análisis decolonial, Canal Facultad de Ciencias Sociales de la Universidad de Chile, 8 septiembre 2014: https://www.youtube.com/watch?v=IE_3ygwasHI\&t=630s [Consultado 5 de enero de 2018].

CURIEL, Ochy, Conferencia Feminismo decolonial latinoamericano y caribeño. Aportes para las prácticas políticas transformadoras, CICODE, Universidad de Granada, 7 de noviembre de 2016: https:// www.youtube.com/watch?v=B0vLIIncsg0\&t=3172s [Consultado: 18 diciembre 2017].

DUSSEL, Enrique, 1492 el Encubrimiento del Otro. Hacia el origen del "mito de la Modernidad", Editores Plural, La Paz, 1994.

DUSSEL, Enrique, "Humanistes d'América: 14 Tesis d'Ética", Conferencia Magistral en Casa América Catalunya: https://www.youtube.com/watch?v=kyqnJWK_IFI\&t=4990s [Consultado 10 de noviembre 2017].

ESPINOSA-MIÑOSO, Yuderkys, "Una crítica descolonial a la epistemología feminista crítica" en El Cotidiano 184, marzo-abril, 2014, pp. 7-12.

FANON, Frantz, Los condenados de la tierra, FCE, México, 1963.

FREIRE, Paulo, Pedagogía de la Esperanza, Siglo XXI, México, 1993.

FREIRE, Paulo, Pedagogy of Indignation. Paradigm, Boulder, Colorado, 2004.

FOUCAULT, Michael, Historia de la sexualidad I. La voluntad de saber, Siglo XXI, Buenos Aires, 1990.

GARGALLO CELENTANI, Francesca, Feminismos desde Abya Yala. Ideas y Proposiciones de las mujeres de 607 pueblos en Nuestra América. Editorial Corte y Confección, México, 2014.

GROSFOGUEL, Ramón, OCHO, Karina, Seminario Transculturalidad, Sesión 1, GLEFAS/UNAM: https:// www.youtube.com/watch?v=PD2MrP5_0U4\&t=3913s [Consultado 11 de febrero de 2018].

GUZMÁN, Adriana, PAREDES, Julieta, Entrevista sobre Feminismo Comunal en Chiapas, en abril de 2014: https://www.youtube.com/watch?v=C6I2BnFCsyk\&t=1212s [Consultado 02 de enero 2018].

HERNÁNDEZ, Aída, Conferencia presentada en el 1er Internacional sobre Transculturalidad, Pensamiento y Estéticas Descoloniales, GLEFAS/UNAM, 8 al 10 de febrero 2016: https://www.youtube.com/ watch? $\mathrm{v}=0 \mathrm{RHq} 8 \mathrm{HDx} 7 \mathrm{aQ}$ [Consultado 13 de febrero de 2018].

LANDER, Edgardo (Ed.), La colonialidad del saber: eurocentrismo y ciencias sociales: perspectivas latinoamericanas, CLACSO, UNESCO, Buenos Aires, 2003.

LUGONES, María, "Multiculturalismo radical y feminismos de mujeres de color", en Revista Internacional de Filosofía Política, № 25, 2005, pp.61-76.

LUGONES, María, "Colonialidad y Género" en Tabula Rasa, N99, Bogotá, julio-diciembre, 2008, pp. 73101.

LUGONES, María, "Hacia un feminismo descolonial" en La manzana de la discordia, Nº6, vol 2, juliodiciembre, 2011, pp. 105-119.

LUGONES, María, "Subjetividad esclava, colonialidad de género, marginalidad y opresiones múltiples" en MONTES, Patricia (Comp), Pensando los feminismos en Bolivia, Conexión Fondos de 
Emancipación, La Paz, 2012, pp. 129-140.

LOYDEN SOSA, Humbelina, SÁNCHEZ BRINGAS, Ángeles, "Cuerpo" en GAMBOA, Susana Beatriz, (Coord) Diccionario de Estudios de Género y Feminismos, Ediciones Biblos, 2da Ed. [1era. Ed. 2007], 2009, pp.74-77.

MALDONADO TORRES, Nelson, "Sobre la colonialidad del ser: contribuciones al desarrollo del concepto", 2004, pp.127-167: http://www.decolonialtranslation.com/espanol/maldonado-colonialidad-delser.pdf [Consultado 15 de febrero de 2018].

MEDINA MARTÍN, Rocío, "Feminismo periféricos, feminismos-otros: una genealogía feminista decolonial por reivindicar" en Revista Internacional de Pensamiento Político, I Época, Vol. 8, 2013, pp. 53-79.

MIGNOLO, Walter (Comp), Género y Decolonialidad, Ediciones del Signo, Colección del Desprendimiento, Buenos Aires, 2014, 2da Ed. [2008].

MIGNOLO, Walter, "Geopolítica de la sensibilidad y del conocimiento. Sobre (de) colonialidad, pensamiento fronterizo y desobediencia epistémica", 2011: http://eipcp.net/transversal/0112/ mignolo/es [Consultado 12 de noviembre de 2017].

MIGNOLO, Walter, "Los estudios culturales: Geopolítica del conocimiento y exigencias/necesidades institucionales" en Revista Iberoamericana, vol LXIX, N² 203, abril-julio, 2003, pp. 401-415.

MIGNOLO, Walter, Conferencia La opción decolonial y la actualidad mundial, CIDOC, 5 de marzo de 2015: https://www.youtube.com/watch?v=WibKFg98M_g [Consultado 07 de enero de 2018].

MIGNOLO, Walter, "Escribir por mandato y para a emancipación ¿descolonización?: autobiografías de resistencia y resistencia a la autobiografía" en ORBE, J. (Comp.) La situación autobiográfica, Corregidor, Buenos Aires.

MOHANTY, Chandra, "Bajo los ojos de occidente. Academia Feminista y discurso colonial" en SUÁREZ NAVAZ, Liliana, HERNÁNDEZ, Aída (Ed.), Descolonizando el Feminismo: Teorías y Prácticas desde los Márgenes, Editorial Cátedra, Madrid, 2008.

OCHOA MUÑOZ, Karina, "Apuntes sobre la ausencia de la noción de "sujeto político femenino" en el pensamiento ilustrado" en Andamios, vol 9, № 20, septiembre-diciembre, 2012, pp. 323-356.

OCHOA MUÑOZ, Karina, Ontología de la dominación. Una perspectiva desde los feminismos descoloniales, Sesión 1, 08 de agosto de 2017: https://www.youtube.com/watch?v=KtsA1uFyeh0 [Consultado 08 de agosto de 2017].

OCHOA MUÑOZ, Karina, Ontología de la dominación. Una perspectiva desde los feminismos descoloniales, Sesión 2, 15 de agosto de 2017: https://www.youtube.com/watch?v=zgQIjQYoF7o [Consultado 15 de agosto de 2017].

PAREDES, Julieta, "Las trampas del patriarcado" en MONTES, Patricia (Comp), Pensando los feminismos en Bolivia, Conexión Fondos de Emancipación, La Paz, 2012, pp. 89-113.

PAREDES, Julieta "Hilando Fino desde el feminismo comunitario. Mujeres creando comunidad" La Paz, 2010.

QUIJANO, Aníbal, Cuestiones y Horizontes. De la Dependencia Histórico-Estructural a Colonialidad/ Descolonialidad del Poder, Antología Esencial, CLACSO, Buenos Aires, 2014.

QUIJANO, Aníbal, "Colonialidad del poder: eurocentrismo y América Latina" en LANDER, Edgardo (Ed.), La colonialidad del saber: eurocentrismo y ciencias sociales: perspectivas latinoamericanas, CLACSO, UNESCO, Buenos Aires, 2003, pp. 201-242.

RESTREPO, Eduardo, ROJAS, Axel, Inflexión decolonial: fuentes, conceptos y cuestionamientos, Colección Política de la Aletidad, IESCP, Universidad Javeriana, Editorial de la Universidad del Cauca, Popayán-Colombia, 2010.

SALAZAR BONDY, Augusto, ¿Existe una filosofía de Nuestra América?, Siglo XXI, México, 1968.

SPIVAK, Gayatri Chakravorty ¿Puede hablar el subalterno? en Orbis Tertius, año 3, N 6, 1998, pp. 175-23: http://www.fuentesmemoria.fahce.unlp.edu.ar/art_revistas/pr.2732/p r.2732.pdf [Consultado 14 enero de 2018].

TORNAY MÁRQUEZ, María Cruz, "Comunicación, decolonialidad y género: una crítica a los estudios de medios de comunicación de masas desde el feminismo decolonial" en SIERRA

WALSH, Catherine (Ed.), Pensamiento crítico y matriz (de) colonial: reflexiones latinoamericanas, Universidad Andina Simón Bolívar, Abya-Yala, Quito, 2005.

WALSH, Catherine. Interculturalidad, Estado Sociedad: Luchas (de) coloniales de Nuestra época, Universidad Andina Simón Bolívar, Ediciones Abya-Yala, Quito, 2009.

WOLF, Naomi, "El mito de la belleza", Editado William Morrow and Co., New York, 1991.

ZEA, Leopoldo, La Filosofía Latinoamericana como Filosofía sin más, Siglo XXI, México, 1969.

ZEA, Leopoldo (Ed.), América Latina en sus ideas, Unesco, Siglo XXI, México, 1986. 


\section{RELACIONES INTERNACIONALES}

Revista académica cuatrimestral de publicación electrónica Grupo de Estudios de Relaciones Internacionales (GERI) Universidad Autónoma de Madrid, España

www.relacionesinternacionales.info

ISSN 1699 - 3950

ff facebook.com/RelacionesInternacionales

twitter.com/RRInternacional 